\title{
Relationship between Circadian Variation of Ambulatory Blood Pressure and Age or Sex in Healthy Adults
}

\author{
Hiroshi Hayashi, Kiyoshi Hatano, Makoto Tsuda, \\ Katsumi Kanematsu, Mari Yoshikane, and Hidehiko Saito
}

\begin{abstract}
Twenty-four-hour ambulatory blood pressure (BP) was monitored in 540 healthy Japanese adults whose casual BP was less than $140 \mathrm{mmHg}$ in systole and less than $90 \mathrm{mmHg}$ in diastole. A total of $304 \mathrm{men}$ and 236 women, ranging in age from 20 to 79 years, with a mean of 40.9 \pm 12.8 years, were studied. BP was measured every 30 min using ABPM-630 (Nippon Colin Co.) for $24 \mathrm{~h}$ in 395 subjects and for $48 \mathrm{~h}$ in 145 subjects. Periodic regression curves were obtained and the coefficients of determination $\left(R^{2}\right)$ was calculated for each periodic component. The periodic regression curves by age and sex were tested statistically for differences in terms of the level (mean value) and the pattern (amplitude and acrophase) of the curves using periodic analysis of covariance (PERCOVA). The periodic regression curve composed of 24- and 12-h periods was fitted satisfactorily to the measured $B P$ values $\left(R^{2}=0.97\right.$ for systolic $B P$ and 0.98 for diastolic BP). The level of the periodic regression curve increased significantly with increasing age, being significantly higher in males than in females. The pattern of BP curve did differ among some age groups but not significantly between the sexes.(Hypertens Res 1992; 15: 127-135)
\end{abstract}

Key Words: normal blood pressure, blood pressure by age and sex, circadian rhythm, Fourier transformation, periodic regression curve

The diagnosis and treatment of hypertension is based on the determination of blood pressure (BP) in the physician's office. However, it has been pointed out that such casual BP measurements may not be the best method of evaluation. As an alternative ambulatory BP monitoring offers the potential advantage of improving patient care $(1,2)$. Portable and noninvasive ambulatory BP monitoring devices for clinical use have been much improved technically in recent years (3). While it would be important to obtain accurate information about the diurnal variation of BP in healthy individuals $(1,4-8)$, such data have not been collected in a large group of Japanese subjects. The present study was therefore carried out to clarify the characteristic features of the diurnal variation and rhythm of BP in 540 normal healthy Japanese adults.

\section{Subjects and Methods}

Subjects

We evaluated 540 healthy Japanese adults, 304 men and 236 women, ranging in age from 20 to 79 years, (mean $40.9 \pm 12.8$ years old; Tables 1,2 ). They were employees of our affiliated hospitals or of local businesses in Nagoya. All were free of cardiovascular disease and had no abnormalities in routine electrocardiogram, chest $\mathrm{x}$-ray, blood chemistry, or urinalysis. Shift workers were not included in this study. Their mean casual systolic/diastolic BP was $<$ $140 \mathrm{mmHg} /<90 \mathrm{mmHg}$, determined on more than three different occasions. Informed consent for participation was obtained from all of the subjects.

\section{Methods}

The 24-h ambulatory BP and pulse rate (PR) were measured automatically using the ABPM-630 (Nippon Colin Co. , Komaki) $(9,10)$ for 25 h in 395 subjects or $49 \mathrm{~h}$ in 145 subjects at 30-min intervals. Measurements were begun between 8:30 and 9:30 AM. Criteria for deleting or editing BP readings were as follows $(11,12)$ : If two successive pressure readings differed by more than $50 \%$ without a concomitant alteration in the heart rate, the second measurement was rejected. About $5 \%$ of the data were discarded according to this criteria.

Any individual who was unable to sleep soundly because of the discomfort caused by cuff pressure or for any other reason was excluded from study. In

From the First Department of Internal Medicine, Nagoya University, School of Medicine, Nagoya, Japan.

This work was supported in part by a research grant for cardiovascular diseases, 63C-6, from the Ministry of Health and Welfare of Japan.

Address for Reprints: Hiroshi Hayashi, M.D., First Department of Internal Medicine, Nagoya University School of Medicine, 65 Tsurumaicho, Showa-ku, Nagoya 466, Japan.

Received April 6, 1992; accepted in revised form November 16, 1992. 
addition, any case with a data deficit of $\geq 2 \mathrm{~h}$ or who required removal of $\geq 10 \%$ of the raw data, was excluded from evaluation.

The averages of the BP and PR readings obtained during a 24-h period, day (from 7:00 to 22: 30) and night (from 23: 00 to 6: 30 ) were expressed as the mean $\pm S D$ (standard deviation).

Measurements were obtained on weekdays during normal activities. During the 24-h or 48-h period, the subjects were instructed to avoid bathing, napping, drinking alcohol, taking part in excessive physical activity and mental stress. Forty-nine-hour continuous recordings were obtained in 145 of the 540 subjects $[73$ men and 72 women, mean age, $30.6+9.2$ years (men) and $32.1+9.0$ years (women)] to assess the reproducibility of the measurements.

BP values obtained by the oscillometric method were used for analysis in this study because the deficit in measurements was less than $4 \%$. To avoid artifacts we discarded the first two measurements obtained in the first hour after the placement of the monitoring device.

Periodic regression analysis was performed to obtain the best fit regression curve to the $\mathrm{BP}$ and PR measured in a $24-\mathrm{h}$ period. The periodic regression curves by sex, age and their combination were tested statistically for differences in terms of the level (mean value) and the pattern (amplitude and acrophase) using periodic analysis of covariance (PERCOVA), an analytical method derived by modifying ANOCOVA (See Appendix).

The degree of fit of the periodic regression curve to the measured data was assessed by the coefficient of determination $\left(R_{2}\right)$. The difference in the level or pattern of the periodic regression curves was considered statistically significant if a $p$-value was less than 0.01 .

\section{Periodic Regression Analysis}

Periodic regression analysis was performed on the values obtained by the $24-\mathrm{h}$ and $48-\mathrm{h}$ measurements

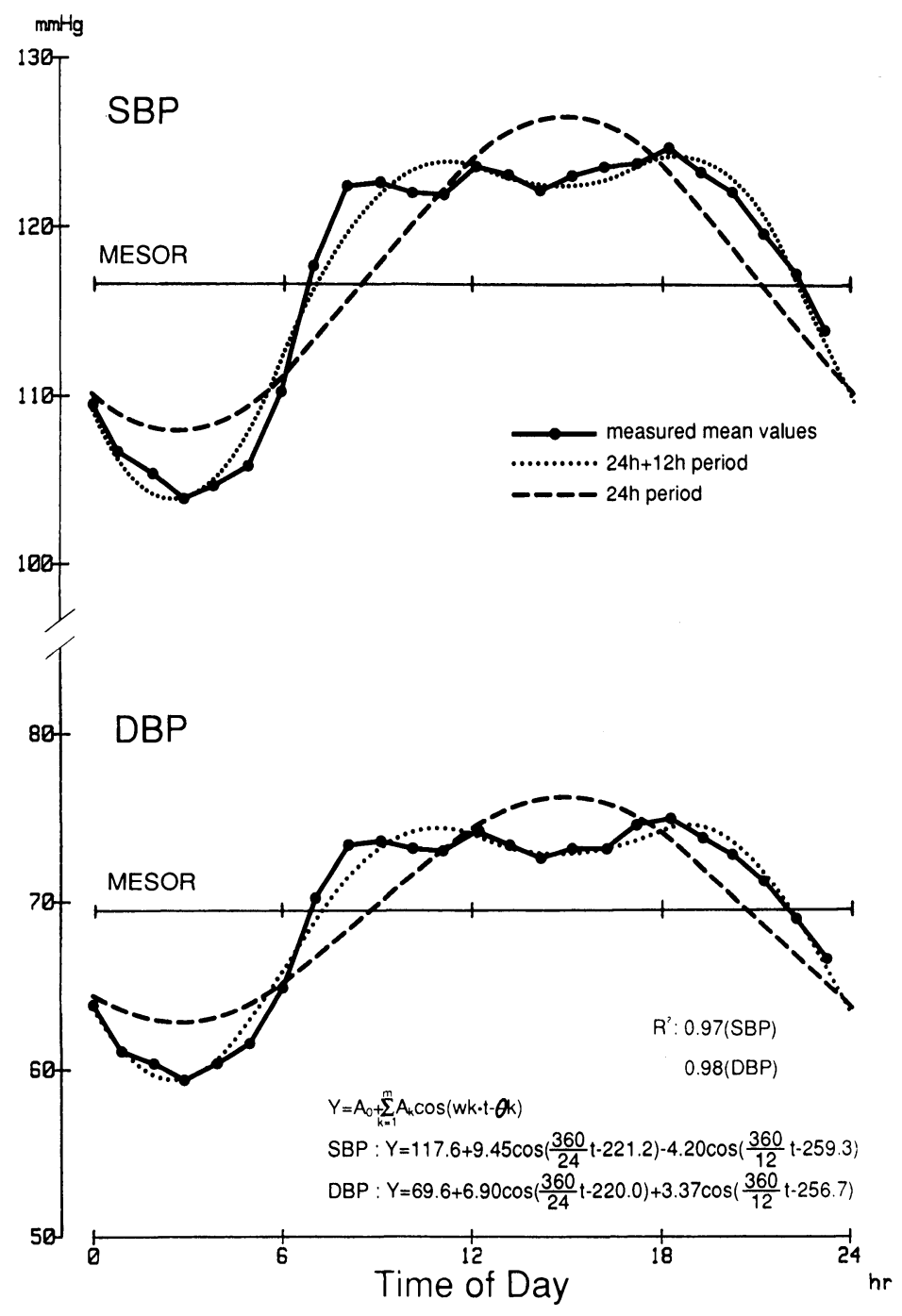

Fig.1. Measured blood pressure and periodic regression curve in normals. SBP, systolic blood pressure; DBP, diastolic blood pressure; MESOR, midline estimating statistics of rhythm-adjusted mean. 
Table 1. Clinical Characteristics of Study Population

\begin{tabular}{lcrr}
\hline & Men & Women & Total \\
\hline$n$ & 304 & 236 & 540 \\
Mean age (yrs) & $41.2 \pm 11.6$ & $40.5 \pm 14.2$ & $40.9 \pm 12.8$ \\
Obesity index (Broca, \%) & $103.7 \pm 11.2$ & $104.0 \pm 14.5$ & $103.8 \pm 12.7$ \\
Wake-up time (hr) & $6: 42 \pm 1.00$ & $6: 36 \pm 0: 54$ & $6: 42 \pm 1: 00$ \\
Retirement time (hr) & $23: 36 \pm 1: 09$ & $23: 00 \pm 1: 18$ & $23: 18 \pm 1: 15$ \\
\hline
\end{tabular}

Table 2. Study Population by Sex and Age Group

\begin{tabular}{cccc}
\hline Age Group (yrs) & Men & Women & Total \\
\hline 20 's & 49 & 65 & 114 \\
30 's & 93 & 41 & 134 \\
40 's & 84 & 62 & 146 \\
50 's & 53 & 37 & 90 \\
$\geq 60$ 's & 25 & 31 & 56 \\
\hline
\end{tabular}

through 12-harmonics $(1,2,3 \ldots \ldots .10,11,12)$ for the former, and 24-harmonics $(1,2,3, \ldots .22,23,24)$ for the latter. One-hour mean values were used for the periodic regression analysis. Fourier transformation (13) was performed and the $R^{2}$ for each periodic component from the 1 st (i.e., $24-\mathrm{h}$ period for $24-\mathrm{h}$ measurement or $48-\mathrm{h}$ period for $48-\mathrm{h}$ measurements) to the 12 th or 24 th $(2-h$ period for either measurements) was calculated for the transformed data (14).

The periodic regression curves with best fit to the values of $24-\mathrm{h}$ or $48-\mathrm{h}$ measurements were obtained using the appropriate number of periodic components with high $R^{2}(15,16)$.

\section{Periodic Analysis of Covariance (PERCOVA)}

PERCOVA was used to examine differences among periodic regression curves with multiple periodic components by applying the principle of periodic regression analysis and of analysis of covariance (ANOCOVA). The differences among periodic regression curves were examined in terms of two components independently, i.e. the level and the pattern. The constant in ANOCOVA corresponds to the level in PERCOVA, and the gradient in ANOCOVA to the pattern in PERCOVA.

\section{Results}

\section{Periodic Regression Curve in All Subjects}

The one-hour mean values of systolic BP and diastolic BP for 540 subjects measured at 30-min intervals throughout a $24-\mathrm{h}$ period are plotted in Fig. 1 (solid circles connected with heavy line). Periodic regression analysis was performed on these values through 12-harmonics and the $R^{2}$ for each periodic component was determined. For the systolic BP, $R^{2}$ for 24 -h and 12 -h periods was 0.81 and 0.16 , respectively, with a total of 0.97 . The $R^{2}$ for periods less than 8 -h was 0.03 . For the diastolic BP, the $R^{2}$ for 24-h and 12 -h periods was 0.79 and 0.19 respectively and the $R^{2}$ for periods less than 8 -h was 0.02 . For
PR, the $R^{2}$ for $24-\mathrm{h}$ and 12 -h periods was 0.77 and 0.16 respectively and the $R^{2}$ for periods less than 8h was 0.07 .

The periodic regression curves to the measured one-hour mean values derived from the equations composed of only a 24-h period (1-harmonic Fourier transformation) are shown in Fig. $1\left(R^{2}=\right.$ 0.81 for systolic $\mathrm{BP}, R^{2}=0.79$ for diastolic $\mathrm{BP}$ and $R^{2}=0.77$ for PR. (Figure not shown for PR.) The periodic regression curves derived from the equations composed of $24-\mathrm{h}$ and 12 -h periods (2-harmonic Fourier transformation) are shown in the same figure $\left(R_{2}=0.97\right.$ for systolic $\mathrm{BP}, R^{2}=0.98$ for diastolic $\mathrm{BP}, R^{2}=0.93$ for $\mathrm{PR}$ ).

In the 145 persons in whom continuous measurements of BP and PR were done for more than $48 \mathrm{~h}$, periodic regression analysis revealed the $R^{2}$ for the 48-h period to be less than 0.01 for either systolic or diastolic BP or PR. Therefore, the periodic regression curves for $\mathrm{BP}$ and $\mathrm{PR}$ were obtained by an equation composed of $24-$ and $12-h$ periods in this study. The periodic regression curves for the first and second days for the BP and PR showed almost the same level and pattern; therefore the reproducibility of systolic BP, diastolic BP and PR was quite high.

The level or MESOR (midline estimating statistic of rhythm-adjusted mean) is also indicated in Fig. 1. The periodic regression curve for $B P$ and $P R$ composed of $24-\mathrm{h}$ and $12-\mathrm{h}$ periods consisted of two peaks, one before noon (first peak) and the other in the evening (second peak). The BP reached the lowest level, the first nadir, at around 3: 00 and then increased sharply in the early morning at around the time of awakening. There was a dip in $\mathrm{BP}$ in mid afternoon, i.e., the second nadir. The BP decreased sharply in late evening followed by the first nadir.

\section{Blood Pressure Variation}

The 24-h variation (mean $\pm \mathrm{SD}$ ) in the systolic and diastolic BP is shown in Fig. 2. For the systolic BP, the upper limit was about $120 \mathrm{mmHg}$ at night and about $140 \mathrm{mmHg}$ during the day. The lower limit for the systolic BP was about $85 \mathrm{mmHg}$ at night and about $105 \mathrm{mmHg}$ during the day. For the diastolic $\mathrm{BP}$, the upper limit was about $70 \mathrm{mmHg}$ at night and about $85 \mathrm{mmHg}$ during the day. The lower limit for the diastolic BP was $50 \mathrm{mmHg}$ at night and about $60 \mathrm{mmHg}$ during the day.

When rhythm analysis is performed by the cosinor method which has only a $24-h$ period, three parameters i.e., MESOR, amplitude and acrophase, 


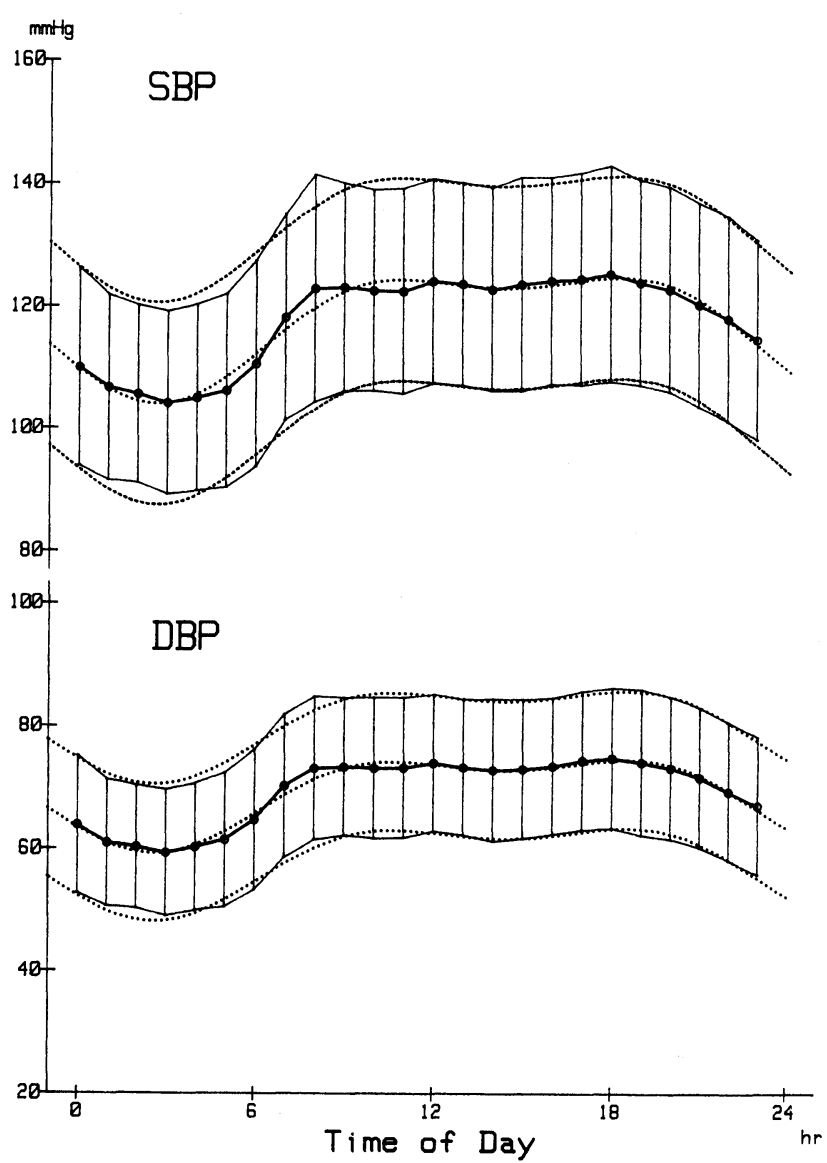

Fig.2. Periodic regression curves (mean $\pm S D$ ) for $S B P$ and DBP. Black dots connected by a solid line indicate the mean values obtained in all subjects.

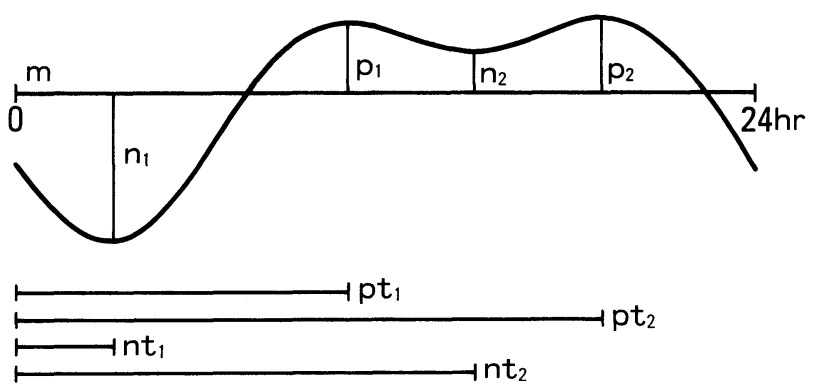

Fig.3. Parameters for periodic regression curve.

are used to define the characteristics of a periodic regression curve. The periodic regression curve in this study, however, was composed of periods of 24-h and 12-h, resulting in two peaks and two nadirs. Therefore, the parameters that defined the characteristics of the curve have been arbitrarily designated as shown in Fig. 3.

The parameters that represent the pattern of periodic regression curves for systolic $\mathrm{BP}$, diastolic $\mathrm{BP}$ and PR are shown in Table 3. The first peak (Peak Time I) for the systolic BP, diastolic BP and PR occurred at around 11: 00, and the second peak (Peak Time II) for the same variables occurred at around 18: 30. The first nadir (Nadir Time I) occurred at around 3: 00, and the second one ( "afternoon dip" ) at around 15: 00. The level (or MESOR) was $117 \mathrm{mmHg}$ for systolic $\mathrm{BP}, 70 \mathrm{mmHg}$ for diastolic BP and $74 \mathrm{bpm}$ for PR.

\section{Periodic Regression Curve by Age and Sex}

The periodic regression curves of systolic BP for men classified by age revealed a significant difference in terms of the level except for those between their 20's and 30's (Figs. 4, 5, Table 4). The BP level of those in their 40's was significantly $(p<$ 0.01 ) higher than that of those in their 50's. The systolic BP pattern revealed significant differences between those in their 20's and 40's, 20's and 50's, 20 's and $\geq 60$ 's, 30's and $\geq 60$ 's, and 40 's and $\geq 60$ 's (Fig. 5).

The diastolic BP level differed significantly among men in all age groups. The level of diastolic BP increased with age but that of men in their 40's was significantly $(p<0.001)$ higher than that of men in their 50's. The diastolic BP pattern revealed a significant difference between men in their 20's and 50's, 20 's and $\geq 60$ 's, 30's and $\geq 60$ 's, and 40 's and $\geq 60$ 's (Fig. 5).

Periodic regression curves of systolic and diastolic $\mathrm{BP}_{\mathrm{S}}$ for women by age (Fig. 6) revealed that the level increased significantly with increasing age, except for the diastolic BP level between women in their 30's and 40's (Figs. 6, 7). The pattern of systolic and diastolic BP in women did not differ significantly between age groups.

With increasing age, the level of systolic and diastolic BP increased at all time periods, e.g. during the day and night and throughout the $24-\mathrm{h}$ period (Table 3).

\section{Discussion}

There is growing evidence that the ambulatory BP can predict target organ damage more effectively than the casual BP $(17,18)$. However, the normal variation of BP during daily activities has not been studied extensively in large populations. Thus, it becomes important to establish standards for interpreting such ambulatory BP data.

\section{Rhythm Analysis}

There are many reports on the rhythm analysis of BP using various methods and the circadian rhythm of BP, both in normal healthy subjects $(6,19-24)$ and in hypertensives (22-27).

In this study, periodic regression analysis was performed to obtain the curve which best fit the measured BP or PR values. The analysis of $R^{2}$ for each periodic component for the periodic regression curve revealed that the curve based on 2-harmonic (24-h and 12-h) Fourier transformations best fit the 
Table 3. Parameters of Periodic Regression Curve for SBP, DBP and PR

\begin{tabular}{cccccccccc}
\hline & MESOR & Peak I & Peak II & Nadir I & Nadir II & Peak TI & Peak TII & Nadir TI & Nadir TII \\
\hline SBP & 117 & 124 & 125 & 104 & 123 & $11: 00$ & $18: 25$ & $2: 40$ & $14: 30$ \\
DBP & 70 & 75 & 75 & 59 & 73 & $10: 40$ & $18: 30$ & $2: 35$ & $14: 25$ \\
PR & 74 & 82 & 81 & 60 & 79 & $11: 00$ & $18: 35$ & $2: 50$ & $15: 24$ \\
\hline
\end{tabular}

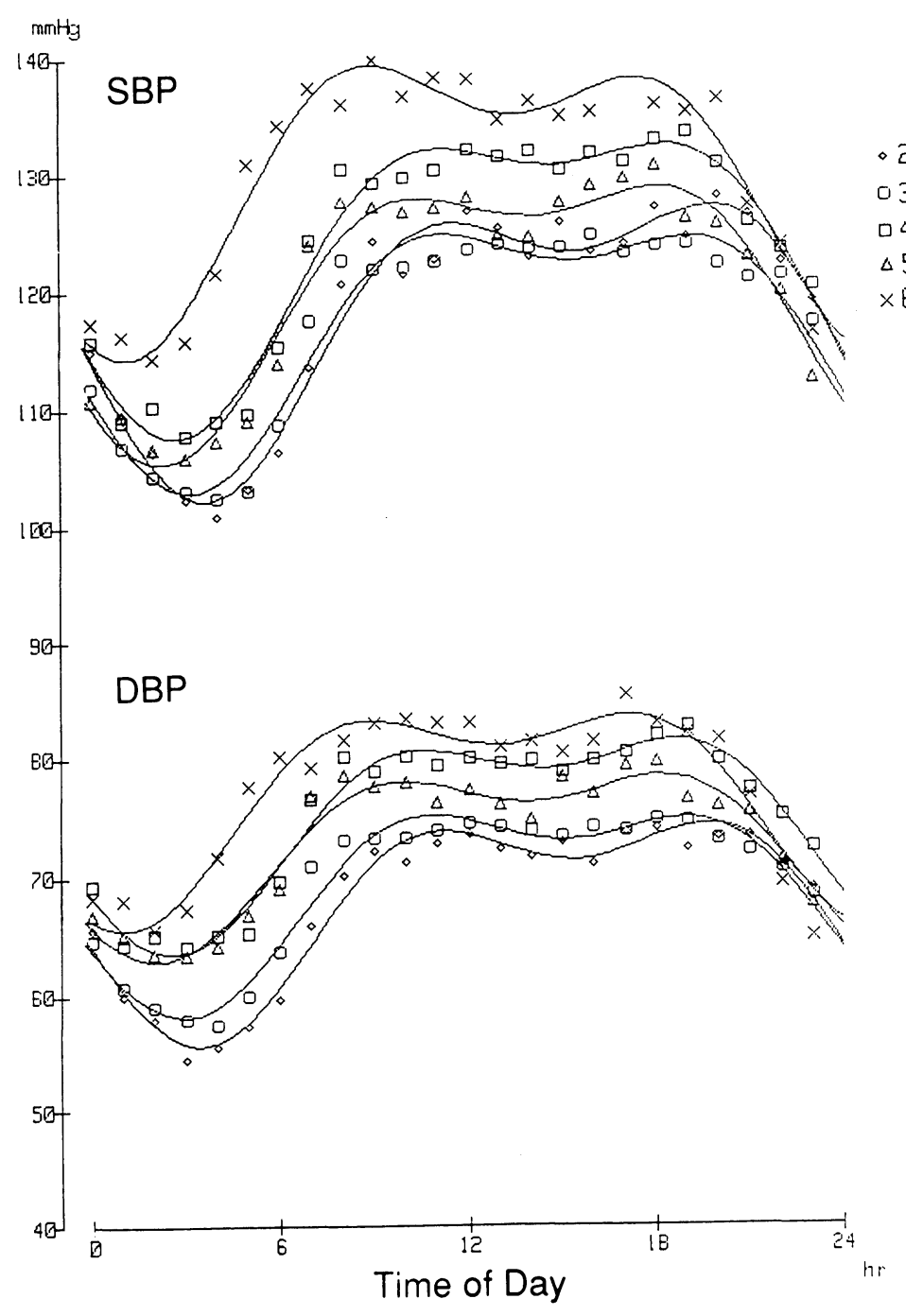

Fig.4. Periodic regression curves for $S B P$ and $D B P$ in normal men by age.

measured BP or PR values. Therefore, the curve had two peaks and two nadirs with differing amplitudes, two peak times, and two nadir times which defined its characteristics. This information had not been described in depth in previous reports. The two nadirs in the diurnal variation of BP and PR seem to be closely related to physical and mental rest. The midnight nadir, nadir I, is induced by sleep and the afternoon dip, nadir II, may be related to the lunch time and coffee break.

The periodic analysis of covariance (PERCOVA) was developed from the modified ANOCOVA to compare differences between periodic regression curves in terms of their level and pattern. When the $\mathrm{BP}$ variation was fitted to the periodic regression curve, its pattern was represented by two components: the amplitude (the peak and the nadir in this study) and the acrophase (time of the peak and of the nadir in this study).

\section{Accuracy and Reproducibility of BP Variation}

The accuracy of measurements obtained by using the ABPM-630 has previously been described (9, 10). Because of body movement or other factors, up to $5 \%$ of the readings were judged unreliable according to the criteria (28) cited in the Methods section so that they were discarded from analysis.

Reproducibility of the ambulatory BP over periods of $48 \mathrm{~h}(29,30)$ and other reported data have shown that the average $\mathrm{BP}$ as well as the pat- 

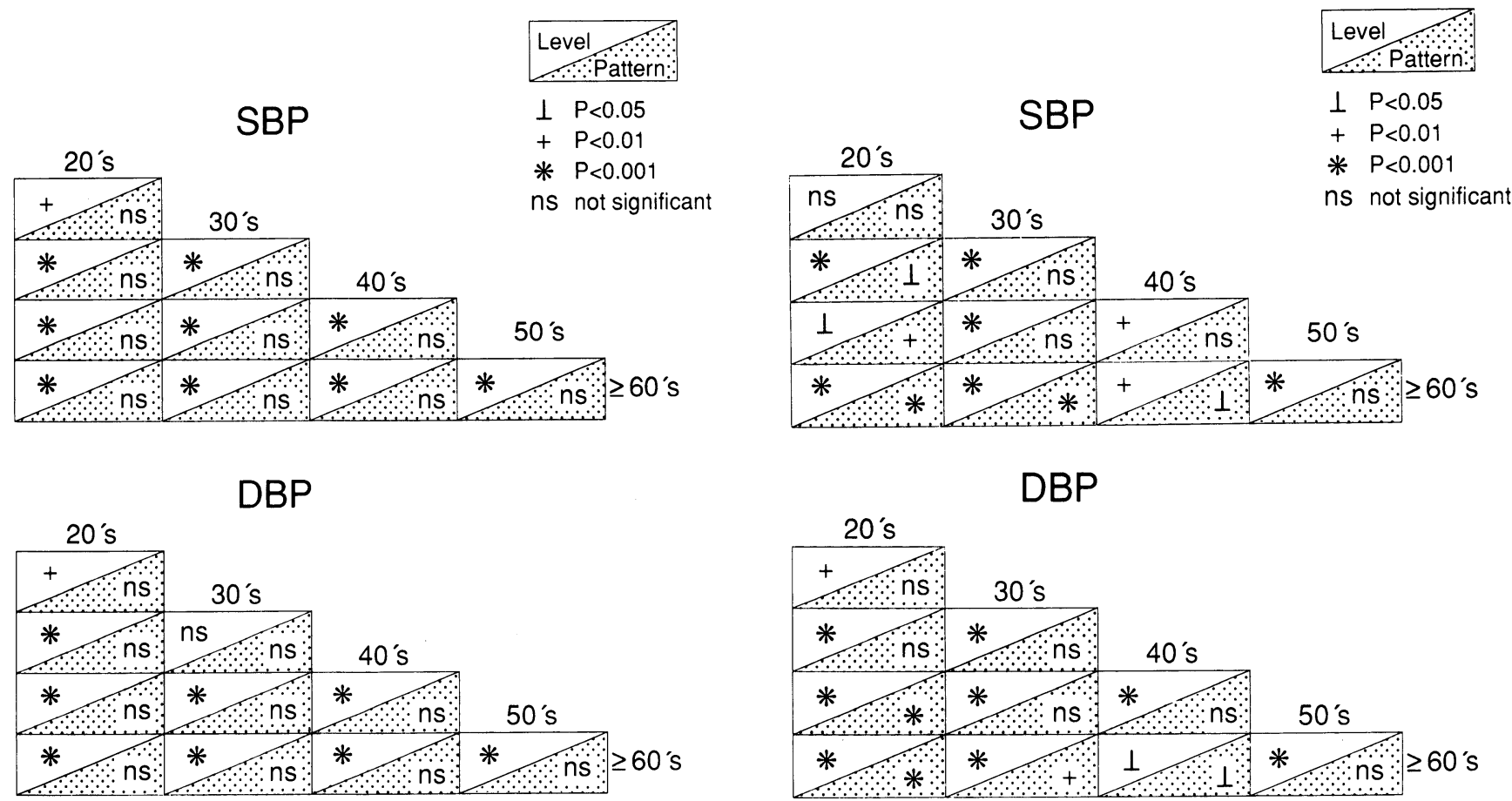

Fig.5. Multiple comparison (Scheffe) of level and pattern differences for systolic and diastolic blood pressure in normal men by age.

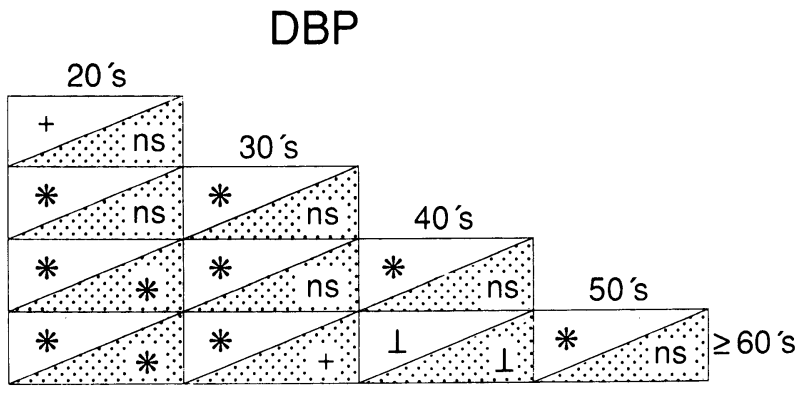

Fig.7. Multiple comparison (Scheffe) of level and pattern differences for systolic and diastolic blood pressure in normal women by age.

Table 4. Mean Systolic and Diastolic Blood Pressures in 24-h, Daytime and Nighttime by Sex and Age

\begin{tabular}{|c|c|c|c|c|c|c|c|c|}
\hline & & & 20's & 30's & 40 's & 50 's & 60 's $\leq$ & Total \\
\hline \multirow{9}{*}{ SBP } & Total & $24 \mathrm{~h}$ & $112 \pm 9$ & $115 \pm 9$ & $120 \pm 14$ & $121 \pm 16$ & $127 \pm 15$ & $117 \pm 13$ \\
\hline & & Day & $117 \pm 10$ & $120 \pm 10$ & $125 \pm 15$ & $126 \pm 16$ & $131 \pm 16$ & $122 \pm 14$ \\
\hline & & Night & $103 \pm 9$ & $106 \pm 10$ & $109 \pm 14$ & $111 \pm 17$ & $117 \pm 15$ & $107 \pm 13$ \\
\hline & Men & $24 \mathrm{~h}$ & $118 \pm 8$ & $118 \pm 9$ & $124 \pm 13$ & $121 \pm 13$ & $130 \pm 16$ & $121 \pm 11$ \\
\hline & & Day & $124 \pm 8$ & $124 \pm 10$ & $130 \pm 13$ & $126 \pm 14$ & $135 \pm 17$ & $126 \pm 12$ \\
\hline & & Night & $108 \pm 8$ & $108 \pm 9$ & $112 \pm 14$ & $109 \pm 13$ & $120 \pm 15$ & $110 \pm 12$ \\
\hline & Women & $24 \mathrm{~h}$ & $106 \pm 7$ & $110 \pm 7$ & $113 \pm 13$ & $119 \pm 19$ & $124 \pm 14$ & $112 \pm 13$ \\
\hline & & Day & $110 \pm 7$ & $114 \pm 7$ & $118 \pm 13$ & $123 \pm 19$ & $128 \pm 14$ & $117 \pm 13$ \\
\hline & & Night & $98 \pm 6$ & $101 \pm 9$ & $105 \pm 14$ & $111 \pm 20$ & $115 \pm 15$ & $104 \pm 14$ \\
\hline \multirow{9}{*}{ DBP } & Total & $24 \mathrm{~h}$ & $66 \pm 6$ & $68 \pm 7$ & $72 \pm 9$ & $74 \pm 10$ & $74 \pm 10$ & $70 \pm 9$ \\
\hline & & Day & $70 \pm 6$ & $72 \pm 7$ & $75 \pm 10$ & $75 \pm 10$ & $77 \pm 11$ & $73 \pm 9$ \\
\hline & & Night & $58 \pm 8$ & $61 \pm 7$ & $64 \pm 9$ & $65 \pm 10$ & $68 \pm 10$ & $62 \pm 9$ \\
\hline & Men & $24 \mathrm{~h}$ & $68 \pm 6$ & $69 \pm 6$ & $75 \pm 9$ & $73 \pm 8$ & $77 \pm 11$ & $72 \pm 8$ \\
\hline & & Day & $72 \pm 6$ & $73 \pm 7$ & $79 \pm 9$ & $77 \pm 9$ & $81 \pm 12$ & $76 \pm 9$ \\
\hline & & Night & $60 \pm 6$ & $61 \pm 7$ & $67 \pm 10$ & $66 \pm 8$ & $70 \pm 10$ & $64 \pm 8$ \\
\hline & Women & $24 \mathrm{~h}$ & $62 \pm 5$ & $65 \pm 5$ & $66 \pm 7$ & $70 \pm 11$ & $72 \pm 9$ & $66 \pm 8$ \\
\hline & & Day & $65 \pm 5$ & $68 \pm 5$ & $69 \pm 7$ & $72 \pm 11$ & $75 \pm 9$ & $69 \pm 8$ \\
\hline & & Night & $55 \pm 5$ & $58 \pm 6$ & $60 \pm 7$ & $64 \pm 12$ & $66 \pm 9$ & $59 \pm 8$ \\
\hline
\end{tabular}

tern of variation are reasonably reproducible $(8,31)$, as we have shown.

Normal Features of Systolic and Diastolic BP

The BP curve showed two peaks during the day with an intervening "afternoon dip." The BP was the lowest during sleep at around 3:00. Our study showed that the blood pressure variation followed a circadian rhythm as has been suggested previously $(5,6,19-24,27)$.

We found the circadian rhythm of BP to be composed not only of a $24-\mathrm{h}$ period but also of a $12-\mathrm{h}$ period. The level (24-h average) of the systolic BP was $117 \pm 13 \mathrm{mmHg}$ and that of the diastolic BP was 


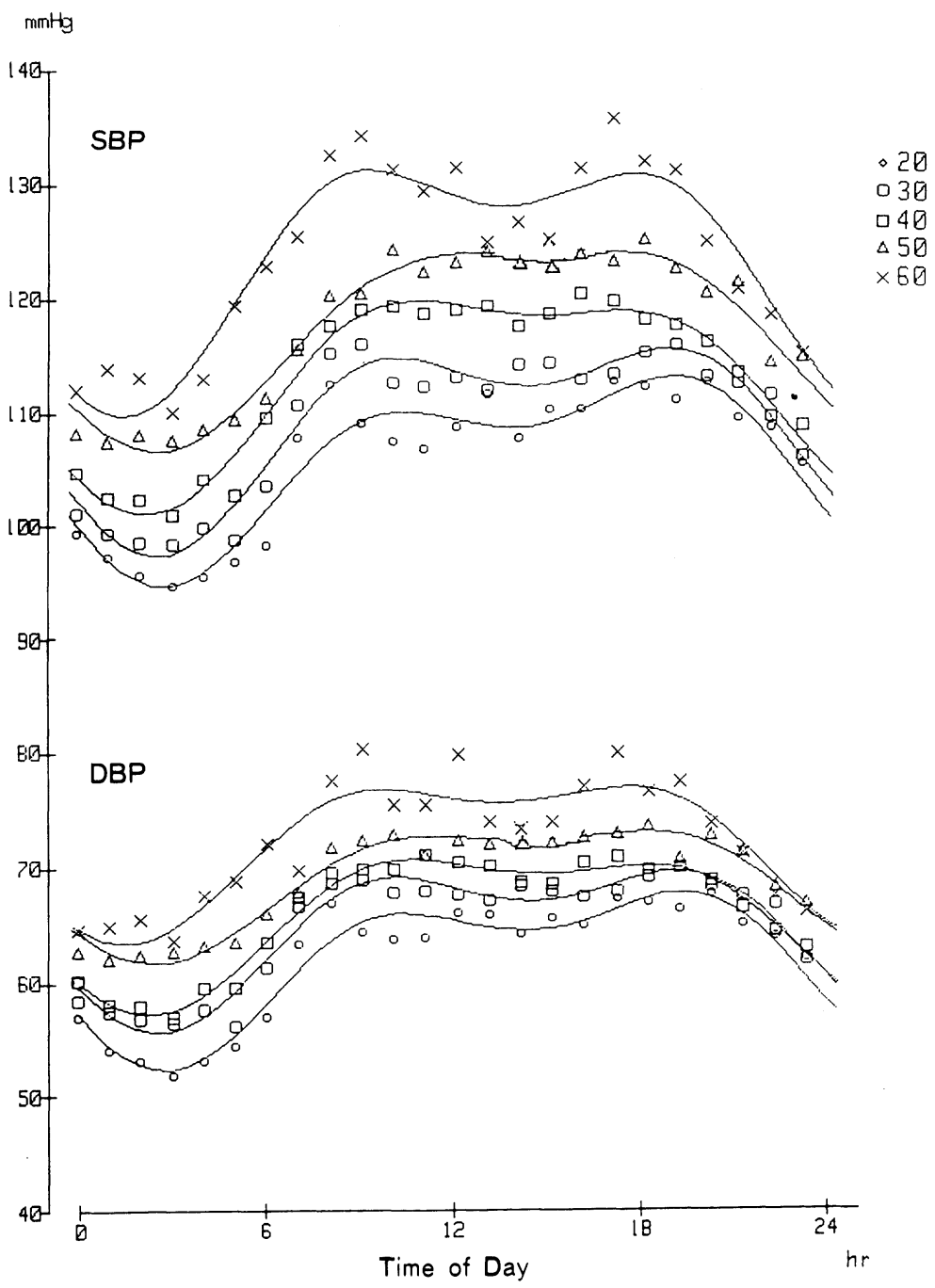

Fig.6. Periodic regression curves for $S B P$ and $D B P$ in normal women by age.

$70 \pm 9 \mathrm{mmHg}$. The normal range of the circadian curve of BP was represented by the mean $\pm 1 \mathrm{SD}$ in this study. The criteria for the upper normal level of casual BP as recommended by WHO (1987) is $140 / 90 \mathrm{mmHg}$, which is reasonable judging from the 24-h ambulatory data observed in the present study of healthy Japanese.

\section{Periodic Components}

The $R^{2}$ for the two periodic components, i.e. the 24-h and 12-h periods, was similar for the systolic $\mathrm{BP}$, diastolic BP and PR, which may imply that the $\mathrm{BP}$ and PR are similarly regulated by extrinsic and intrinsic factors.

\section{Sex and Age Differences}

Analysis of the systolic BP level in men by age group revealed significant differences between all groups except between those men in their 20's and 30 's, indicating their similar activities and life styles.

A significant difference in the systolic and diastol- ic BP patterns was more frequently seen between those men in their 20's, 60's and other age groups than among other age groups. This may be related to the difference in life style: a late nadir time I and peak time II in subjects in their 20's and an early nadir time I and peak time I in those over age 60.

These findings may be attributed to differences in awakening time and retirement time between age groups. The average wake-up time was $6: 42$ and 6:54 in subjects in their 60's and 20's, respectively. The average retirement time was 22:12 and 23: 42 in subjects in their 60's and 20's, respectively.

The periodic regression curve for systolic and diastolic BP in women by age group revealed a significant difference in the level between all age groups except for the diastolic BP between those in their 30 's and 40's. A significant difference in the pattern was not observed between any age group. This may be explained by the small difference in the peak time and nadir time as well as the amplitude among age groups. 


\section{Study Limitations}

The measurements were performed every $30 \mathrm{~min}$ which limits the precise analysis of rhythm especially within $8 \mathrm{~h}$. Although the monitoring device is silent, the pressure of the cuff may have disturbed the sleep of some subjects producing some artifacts.

The criteria for normotension were based on the casual BP which was uniformly set at SBP $<140$ $\mathrm{mmHg}$ and $\mathrm{DBP}<90 \mathrm{mmHg}$, without taking the subject's age into account. This may have caused the BP level of the younger groups to be erroneously higher than the true normal.

\section{Clinical Implications}

The physician must consider the cost-benefit relationship when beginning long-term treatment for hypertension (32). Whether the normal range of blood pressure obtained in the Japanese adults tested in this study is appropriate requires additional prospective study based on the long-term evaluation of mortality and morbidity. Also additional research is required to standardize methods for the ambulatory monitoring of $\mathrm{BP}$ and to better define the normal range including variables based on racial differences.

\section{Acknowledgement}

The authors are grateful to Mr. Norio Sugimoto for his statistical advice.

\section{Appendix}

\section{Periodic Analysis of Covariance (PERCOVA)}

When the measured $P$ quantities in time series data $y$ $\left(y_{i 1}, . . y_{i j} . . y_{i p} \ldots\right)$ observed at $\mathrm{t}\left(t_{1} . . t_{j} . . t_{p}\right)$ are present in a number of groups $\left(A_{1} . . A_{i} . . A_{a}\right), m$-term Fourier series is fitted $(2 m \leqq p, m+1$ term or higher is considered an error $\varepsilon)$

$$
\begin{aligned}
y & =\frac{a_{0}}{2}+\sum_{k=1}^{m}\left\{a_{k} \cdot \cos \left(\frac{2 \pi k t}{T}\right)+b_{k} \cdot \sin \left(\frac{2 \pi k t}{T}\right)\right\}+\varepsilon \cdots \cdots \cdots(1) \\
& =A_{0}+\sum_{k=1}^{m} A_{k} \cdot \cos \left(\frac{2 \pi k t}{T}-\theta_{k}\right)+\varepsilon
\end{aligned}
$$

we have used the least squares estimates employing the least square method with linearization about $x$ from Eq. (1), if the following are set:

$$
\begin{aligned}
& \beta_{0}=\frac{a_{0}}{2}, \beta_{2 k-1}=a_{k}, \beta_{2 k}=b_{k} \\
& \quad x_{2 k-1}=\cos \left(\frac{2 \pi k t}{T}\right), x_{2 k}=\sin \left(\frac{2 \pi k t}{T}\right)
\end{aligned}
$$

The linearized equation is transformed to multiple regression form using matrix and vector as follows:

$$
y=X_{\beta}+\varepsilon \quad \text { Least square estimator: } \beta=\left[X^{\prime} X\right]^{-1} X^{\prime} y
$$

In analysis of covariance (ANOCOVA) the following two different regression equations, (2) and (3), are fitted to the data and difference between them are tested by analysis of variance (ANOVA).

Regression equation by group $\left(A_{i}\right)$

$y_{i j}=A_{0 i}+\sum_{k=1}^{\mathrm{m}} A_{k i} \cdot \cos \left(\frac{2 \pi k t_{j}}{T}-\theta_{k i}\right)+\varepsilon_{i j} \cdots \cdots \cdots \cdots \cdots \cdots \cdots(2)$

$$
\begin{gathered}
\text { where } i=i, j=1, \cdots, p \\
\text { Total regression equation }\left(\mathrm{A}_{1} \ldots, \mathrm{A}_{i} \ldots, \mathrm{A}_{a}\right) \\
y_{i j}=A_{0 T}+\sum_{\mathrm{k}=1}^{\mathrm{m}} A_{K T} \cdot \cos \left(\frac{2 \pi k t_{j}}{\mathrm{~T}}-\theta_{K T}\right)+\varepsilon_{i j} \cdots \cdots \cdots \cdots \cdots(3) \\
\text { where } i=1, \cdots, a, j=1, \cdots, p
\end{gathered}
$$

ANOCOVA is obtained by transforming regression equations (2) and (3) to the above multiple regression form or periodic regression equation.

The calculated results are summarized in the PERCOVA table:

\begin{tabular}{lcccc} 
Parameter & $\begin{array}{l}\text { Sum of } \\
\text { Square(SS) }\end{array}$ & $\begin{array}{c}\text { Degree of } \\
\text { Freedom(DF) }\end{array}$ & $\begin{array}{c}\text { Mean Sum of } \\
\text { Square (MS) }\end{array}$ & $F$-value \\
\hline Total Period & $S_{\beta T}$ & $\phi_{\beta T}$ & $V_{\beta T}=\frac{S_{\beta T}}{\phi_{\beta T}}$ & $F_{\beta T}=\frac{V_{\beta T}}{V_{R}}$ \\
Group Difference & $S_{A}$ & $\phi_{A}$ & $V_{A}=\frac{S_{A}}{\phi_{A}}$ & $F_{A}=\frac{V_{A}}{V_{R}}$ \\
Non-Parallelism & $S_{D}$ & $\phi_{D}$ & $V_{D}=\frac{S_{D}}{\phi_{D}}$ & $F_{D}=\frac{V_{D}}{V_{R}}$ \\
Residual & $S_{R}$ & $\phi_{R}$ & $V_{R}=\frac{S_{R}}{\phi_{R}}$ & \\
\hline Total & $S_{T}$ & $\phi_{T}$ &
\end{tabular}

Three parameters were tested for the following reasons:

1) The total period was tested to evaluate whether the total periodic regression equation was significant.

When $F_{\beta T} \geqq F\left(\phi_{\beta T}, \phi_{R}, \alpha\right)$, it is significant with the level of significance $\alpha$.

2) The group difference (or the level) was tested to evaluate the mean value in each group when the periodic regression equation by group was non-parallel.

When $F_{A} \geqq F\left(\phi_{A}, \phi_{R}, \alpha\right)$, it is significant with the level of significance $\alpha$.

3) Non-parallelism (or the pattern) was tested to evaluate whether the periodic regression equation by group was parallel.

When $F_{D} \geqq F\left(\phi_{D}, \phi_{R}, \alpha\right)$, it is significant with the level of significance $\alpha$.

\section{References}

1. Drayer JIM, Weber MA : Definition of normalcy in whole-day ambulatory blood pressure monitoring. Clin Exp Hypertens, 1985 ; A7 : 195-204.

2. Mancia G, Parati G, Pomidossi G, Di Rienzo M : Validity and usefulness of non-invasive ambulatory blood pressure monitoring. J Hypertens 1985; 3 (suppl 2) : S 5-S 11.

3. Harshfield GA, Pickering TG, Blank S, et al: Ambulatory blood pressure monitoring: Recorders, applications, and analyses. In Ambulatory Blood Pressure Monitoring, ed. Weber MA, Drayer JIM. New York, Springer-Verlag, 1984; pp 1-7.

4. Whallace JM, Thornton WE, Kennedy HL, et al : Ambulatory blood pressure in 199 normal subjects, a collaborative study. In "Ambulatory Blood Pressure monitoring". Ed. Weber MA-Drayer JI. SpringerVerlag, New York, 1984; pp 117-127.

5. Pickering TG, Harshfield GA, Kleinert HD, Blank 
S, Laragh JH: Blood pressure during normal daily activities, sleep, and exercise : Comparison of values in normal and hypertensive subjects. JAMA 1982 ; 247 : 992-996.

6. Drayer JIM, Weber MA, Hoeger WJ : Whole-day BP monitoring in ambulatory normotensive men. Arch Intern Med 1985 ; 145 : 271-274.

7. Des Combes BJ, Porchet M, Waeber B, Brunner HR : Ambulatory blood pressure recordings: Reproducibility and unpredictability. Hypertension 1984 ; 6 : 110-114.

8. Weber MA, Drayer JIM, Nakamura DK, Wyle FA : The circadian blood pressure pattern in ambulatory normal subjects. Am J Cardiol 1984 ; 54 : 115-119.

9. White WB, Lund-Johansen P, McCabe EJ : Clinical evaluation of the Colin ABPM 630 at rest and during exercise : an ambulatory blood pressure monitor with gas-powered cuff inflation. J Hypertens 1989 ; 7 : 477483.

10. Imai $\mathrm{Y}$, Abe K, Sasaki S et al : Determination of clinical accuracy and nocturnal blood pressure pattern by new portable device for monitoring indirect ambulatory blood pressure. Am J Hypertens 1990 ; 4 : 293341.

11. White WB, Schulman P, McCabe EJ, Dey HM : Average daily blood pressure, not office blood pressure, determines cardiac function in patients with hypertension. JAMA $1989 ; 261$ : 873-877.

12. Pickering TG, Harshfield GA, Kleinert HD, Blank $\mathrm{S}$, Laragh $\mathrm{JH}$ : Comparisons of blood pressure during normal daily activities, sleep, and exercise in normal and hypertensive subjects. JAMA 1984 ; 247: 992996.

13. Germano G, Dimiani S, Ciavarella M, Appolloni A, Ferrucci A, Corsi V : Detection of a diurnal rhythm in arterial blood pressure in the evaluation of 24-hour antihypertensive therapy. Clin Cardiol 1984 ; 7 : 525535.

14. Brandt $\mathrm{S}$ : Statistical and computed method in data analysis, 2nd ed, North Holland,1976.

15. Morrison DF : Profile analysis. Multivariate Statistical Methods, 2nd ed. New York, McGraw-Hill, 1976 ; pp 205-216.

16. Marler MR, Jacob RG, Lehoczky JP, Shapiro AP : The statistical analysis of treatment effects in 24-hour ambulatory blood pressure recordings. Statist Med $1988 ; 7: 697-716$.

17. Perloff D, Sokolow M, Cowan R: The prognostic value of ambulatory blood pressures. JAMA 1983 ; 249 : 2792-2798.

18. Devereux RB, Pickering TG, Harshfield GA, et al : Left ventricular hypertrophy in patients with hypertension: importance of blood pressure response to regularly recurring stress. Circulation 1983 ; 68 : 470476.
19. Halberg F : Chronobiology of human blood pressure 2nd edition. August 1986. Medtronic Seminar.

20. Halberg F, Drayer JIM, Cornelissen G, Weber MA : Cardiovascular reference data base for recognizing circadian mesor- and amplitude-hypertension in apparently healthy men. Chronobiologica $1984 ; 11$ : 275

21. O'Brien E, Perry I, Sheridan J, Atkins N, O'Malley $\mathrm{K}$ : Application of cusums to ambulatory blood pressure data : a simple statistical technique for detecting trends over time. J Hypertens 1989 ; 7 : 707-709.

22. Millar-Craig MW, Bishop CN, Raftery EB: Circadian variation of blood-pressure. Lancet $1978 ; 1$ : 795-797.

23. Drayer JIM, Weber MA, Nakamura DK : Automated ambulatory blood pressure monitoring: A study in age-matched normotensive and hypertensive men. Am Heart J 1985 ; 109 : 1334-1338.

24. Moore-Ede MC, Czeisler CA, Richardson GS : Circadian timekeeping in health and disease. Part 1. Basic properties of circadian pacemakers. $N$ Engl J Med 1983; 309 : 469.

25. Tochikubo O, Umemura S, Noda K, Kaneko Y: Variability of arterial blood pressure and classification of essential hypertension by multivariate statistical analysis. Jpn Circ J $1981 ; \mathbf{4 5}$ : 781-799.

26. Messerli FH, Glade LB, Ventura HO et al : Diurnal variations of cardiac rhythm, arterial pressure, and urinary catecholamines in borderline and established essential hypertension. Am Heart J 1982 ; 104 : 109114.

27. Drayer JIM, Weber MA, DeYoung JL, Wyle FA : Circadian blood pressure patterns in ambulatory hypertensive patients : effects of age. Am J Med 1982; 73 : 493-499.

28. Kennedy HL, Padgett NE, Horan MJ : Performance reliability of the Del Mar Avionics noninvasive automated blood pressure investment in clinical use. $A m b$ Electrocardiol ; $1979 ; 1$ : 3-6.

29. Weber MA, Drayer JIM, Wyle FA, DeYoung JL: Reproducibility of the whole-day blood pressure pattern in essential hypertension. Clin Exp Hypertens 1982 ; A 4 : 1377-1390.

30. Mann S, Millar-Craig MW, Balasubramanian V, Cashman PMM, Raftery EB : Ambulant blood pressure : reproducibility and the assessment of interventions. Clin Sci 1980; 59: 497-500.

31. James GD, Pickering TG, Yee LS, Harshfield GA, Riva S, Laragh $\mathrm{JH}$ : The reproducibility of average ambulatory, home, and clinic pressures. Hypertension $1988 ; 11$ : $545-549$.

32. Littler WA, Honour AJ, Phil D, Pugsley DJ, Sleight $\mathrm{P}$ : Continuous recording of direct arterial pressure in unrestricted patients: its role in the diagnosis and management of high blood pressure. Circulation 1975 ; 51 : 1101-1106 